\title{
EL DESAFÍO DE BILLY BUDD. DILEMAS MORALES Y DIMENSIÓN INSTITUCIONAL DEL DERECHO
}

\section{GUILLERMO LARIGUET CONICET} Centro de Investigaciones de la Facultad de Filosofía y Humanidades de la Universidad Nacional de Córdoba, Argentina glariguet@yahoo.com

RESUMEN: En este artículo se analiza el problema especial que tiene que enfrentar un agente moral cualificado institucionalmente, en específico un juez de un sistema jurídico cuando tiene que decidir sobre una situación que supone un dilema moral o jurídico. A partir de la historia de Melville, Billy Budd, se examinan los principales desafíos que el caso de Billy Budd plantea a la filosofía jurídica y la filosofía moral. Se muestra cómo el desafío es discutido por los filósofos del derecho en términos de la dimensión institucional del derecho, y por los filósofos morales cuando tratan las cosas en términos de una ética kantiana, en oposición a una ética de la virtud. Por último se sugiere la necesidad de contar con una visión más integrada de la filosofía moral y la filosofía del derecho.

PALABRAS ClAVE: dilemas morales, dimensión institucional del derecho, ética kantiana, ética de la virtud, resolución racional

SUMMARY: This paper analyzes the special problem that an institutionally qualified moral agent faces. In particular, it deals with the case of a judge in a legal system facing a moral or legal dilemma. By focusing on Melville's Billy Budd, the text examines the main challenges that the Billy Budd case poses to legal and moral philosophy. It shows how the challenge is discussed by philosophers of law and by moral philosophers. Finally, it suggests the need for a more integrated perspective in moral and legal philosophy.

KEY WORDS: moral dilemmas, institutional dimension of Law, Kantian ethics, ethics of virtue, rational resolution

\section{Introducción}

Si los dilemas morales fuesen posibles, ${ }^{1}$ básicamente ellos enfrentarían a un agente moral $S$ a una situación en que está obligado a hacer $A(O A)$ y está obligado a hacer $B(O B)$ pero no puede satisfacer simultáneamente estas dos obligaciones y tanto $A$ cuanto $B$ llevan a resultados incompatibles (McConnell 2002, p. 2). Si el agente $S$ satisface $A$, violará $B$; si satisface $B$, violará $A$ (De Haan 2001, p. 283). Por ello suele afirmarse que, sea cual sea el camino ( $A$

\footnotetext{
${ }^{1}$ Como se sabe, para algunos filósofos éstos no son posibles; véase, por ejemplo,
} Conee 1982, pp. 87-97. 
o B) adoptado por el agente, éste habrá hecho algo "malo": 2 habrá violado una obligación moral o jurídicamente relevante. La violación de una obligación puede, también, analizarse en términos de qué valor subyacente se ha sacrificado y, desde luego, queda abierta la posibilidad de examinar la obligación dejada a un lado en términos de "residuo" y "pérdida moral".

Además de lo anterior hay que señalar que las obligaciones que entran en conflicto en un dilema pueden pertenecer al mismo sistema normativo, en cuyo caso se trata de un conflicto interno o intrasistemático de obligaciones, o bien pueden pertenecer a sistemas normativos distintos, en cuyo caso se trata de un conflicto externo o intersistemático de obligaciones. ${ }^{3}$

En este trabajo, deseo centrarme en el vínculo entre dilemas y "dimensión institucional" del derecho." La principal tesis que voy a desarrollar subraya la importancia de las restricciones que tiene un juez para resolver un conflicto dilemático. La cuestión es que estas restricciones son discernibles de aquellas que experimenta un agente moral ordinario. Parte de mi análisis se dirigirá a subrayar el modo en que esta dimensión afecta ciertos principios y valores que se deben tener en cuenta; también se dirige a los argumentos aceptables en la deliberación cuando el elemento institucional está presente.

Con el testimonio de mis argumentos intentaré poner en evidencia dos cosas. La primera es que si bien la cuestión no ha atraído lo suficiente a los circuitos de los filósofos morales y del derecho, ella no carece de consecuencias relevantes. La segunda es que, a partir del desarrollo de esta tesis, pueden obtenerse sugerencias para análisis independientes de cuestiones como la autoridad del derecho y el alcance de su presunta autonomía en relación con un campo como el de la moral. Mi estrategia no consiste en ocuparme directamente de estos problemas que siguen cautivando a grandes teóricos del derecho, sino más bien mostrar, desde la perspectiva de mi tesis, por qué las cuestiones sobre la autoridad y la autonomía del derecho siguen cautivando.

Para fundar el análisis voy a partir de las siguientes dos distinciones. La primera separa dos tipos de agentes: lo que denomino

${ }^{2}$ Por ejemplo, Williams 1993, p. 101.

${ }^{3}$ Por ejemplo, von Wright 1968, p. 78.

${ }^{4}$ La frase "dimensión institucional del derecho" es bifronte pues puede referir a la institución derecho, o a las instituciones que integran el derecho. Espero que el uso del singular y el plural en mi texto aclare uno y otro sentidos. 
un agente moral simple $\mathrm{u}$ ordinario y lo que denomino un agente cualificado institucionalmente por el derecho. Por "agente moral simple u ordinario" entiendo cualquier sujeto que puede enfrentar situaciones dilemáticas. Por "agente cualificado institucionalmente" entiendo cualquier sujeto que tenga que enfrentar situaciones dilemáticas a partir de un rol y un trasfondo institucional como el que suministra el derecho. El supuesto paradigmático de agente cualificado institucional que tendré en cuenta es el de los "jueces" de cualquier sistema jurídico. Admitiendo la posibilidad de que los jueces tengan que enfrentar conflictos dilemáticos, la segunda distinción separa lo que - líneas atrás - llamé conflictos internos o intrasistemáticos de obligaciones respecto de los conflictos externos o intersistemáticos de obligaciones.

Además recurriré a un experimento mental que se basa en el conocido caso de Billy Budd, popularizado por la historia del mismo nombre que escribió Melville. Se trata de un caso literario, inspirado en una historia real, que ha llamado la atención de filósofos como Peter Winch, Konstantin Kolenda y Joseph Raz. ${ }^{5}$

¿Por qué parto de este ejemplo? La respuesta a esta pregunta requiere distinguir tres aspectos. El primero es que el caso de Billy es resuelto por el capitán Vere, un juez o agente cualificado institucionalmente que debe enfrentarse a un dilema particular: si procede o no condenar a Billy, un marinero de su tripulación. El ejemplo es muy específico: no busca ciudadanos como Antígona que claman por libertad religiosa ni busca estadistas como Agamenón que tienen que decidir si matan a la hija ni estadistas como Creón que tienen que decidir si desprotegen la postura de la sobrina.

El segundo aspecto es que el capitán Vere se enfrenta al conflicto de dos normas ${ }^{6}$ diferentes. Por una parte, una norma jurídica perteneciente al código de guerra según la cual la acción de matar tiene el mismo reproche sin importar si la acción fue cometida con o sin intención y donde la consecuencia prevista es la pena capital. Por la otra parte, una norma según la cual es necesario distinguir el caso de matar con intención del caso de matar sin intención. La necesidad de la distinción se apoya en la creencia de que matar sin intención

\footnotetext{
${ }^{5}$ Véanse Winch 1972, Kolenda 1975 y Raz 2000.

6 Aquí estoy empleando el término 'norma' de una manera lo suficientemente laxa como para comprender la idea de regla o principio moral o jurídico, sin preocuparme por establecer una clasificación particular.
} 
— como es el supuesto caso de Billy — ${ }^{7}$ debe tener un reproche penal o moral menor que el imputado a matar con intención.

De acuerdo con el tercer aspecto, el conflicto que experimenta Vere puede ser analizado o como un conflicto interno de obligaciones o como un conflicto externo de obligaciones. Supóngase, por el momento, que el caso no es un conflicto interno en el sistema jurídico del juez, porque tal sistema proporciona una solución consistente. Supóngase que tampoco es un conflicto interno desde el punto de vista de un sistema moral, pues éste también proporciona una solución consistente. Si ambas suposiciones son viables, ello hace que el caso colapse en un conflicto externo de obligaciones: el conflicto surge de intentar aplicar al mismo caso dos sistemas normativos incompatibles. Pero, si es así, ¿por qué resulta interesante ocuparse de un conflicto externo de obligaciones cuando el sistema jurídico ya tiene una respuesta para el caso? ¿Plantear un ejemplo en términos de conflicto externo de obligaciones disuelve la relevancia del problema?

En parte, lo puesto en el centro de la pregunta es verdadero. Ello es así porque, en ocasiones, la categoría de "conflicto externo" suele emplearse con la finalidad de "disolver dilemas". Así, una manera común de disolución es la que dice: este conflicto no es interno sino externo. Tiene solución en este sistema, aunque a usted le guste la solución de un sistema distinto. Esta manera de ver las cosas peca de apresurada y simplista. ¿Por qué el ejemplo es apropiado? Lo es porque muestra que la pretendida "autonomía del derecho" sigue siendo todavía "un nombre" y no la "respuesta filosófica indisputable" a un problema. Cuando se verifica una situación de indeterminación en el derecho, es común acudir a la moral y no a un derecho crítico; en cambio, cuando hay un conflicto en un sistema de moral positiva, no se acudirá más que a otro sistema moral, asumido como crítico. En resumen: el derecho no parece funcionar con la misma autonomía que la moral pues no es usual acudir a otro sistema jurídico que se asuma como crítico. Aunque el caso de Billy tenga respuesta en el sistema jurídico, no nos parece raro decir que ésta es injusta o inmo$\mathrm{ral}^{8}$ y que esta injusticia o inmoralidad tienen que ser consideradas en el razonamiento jurídico. Se podría pensar que mi razonamiento se dirige a defender que el derecho no tiene la misma autonomía

${ }^{7}$ Un supuesto que, en términos de dogmática penal, no se puede calificar de "homicidio intencional o doloso", pero sí se podría calificar bajo los conceptos de homicidio imprudente o incluso preterintencional, lo cual depende de la reconstrucción adoptada.

${ }^{8}$ Porque asigna el mismo reproche a acciones de matar cuya distinción, en cuanto a la presencia o ausencia de intención, parece relevante. 
que la moral. No exactamente. Esto no se puede afirmar sin más, pues, como se verá, es posible articular un razonamiento jurídico más "complejo" que permita corregir o criticar, dentro del derecho, aspectos deficientes de un razonamiento jurídico simple.

El análisis que propongo requiere:

- Describir brevemente los principales problemas del caso de Billy que Melville expone en su narración (sección 1).

- Caracterizar el modo en que entenderé la dimensión institucional del derecho y plantear los principales problemas que ella suscita en conexión con un caso como el de Billy (sección 2).

- Mostrar algunas soluciones posibles que darían los filósofos del derecho a este caso. Para ello describiré brevemente tres posibles respuestas: las dos primeras se mantienen "dentro" del derecho, pero sus diferencias son que una se apoya en un razonamiento jurídico que llamo "simple" y la otra en un razonamiento jurídico que llamo "complejo". La tercera respuesta "se sale" del derecho y busca auxilio en la moral (sección 3).

- Presentar las soluciones básicas que suministrarían los filósofos morales. Reconstruiré estas propuestas de solución en dos versiones éticas diferentes: una ética de la virtud y una ética kantiana (sección 4).

- Resaltar algunos de los aspectos tratados en el artículo y dejar abierta una cuestión importante para un futuro trabajo (sección 5).

\section{El caso de Billy Budd}

El caso del Billy Budd de Melville está centrado en tres personajes: Billy Budd, el prototipo de hombre "noble" e "inocente"; Claggart, el prototipo del hombre trepador y envidioso, y el capitán Vere, el prototipo de hombre reflexivo e imparcial.

Los hechos del caso son los siguientes: Claggart acusa en falso a Budd de estar tramando un motín en el Bellipotent. Los motivos obedecen a una difusa relación de envidias y a raíces profundas del carácter de Claggart. Ante semejante infundio, la "reacción" no premeditada de Budd es propinar un golpe en el rostro a Claggart. Melville deja en claro que Budd lo hace "sin intención", y el resultado de este golpe es la muerte inmediata de Claggart. 
El capitán Vere se encuentra frente al dilema de aplicar la regla del código de guerra que sanciona el homicidio con pena capital o seguir sus convicciones morales y, al menos, atenuar la pena sobre la base de que el homicidio no fue ejecutado con intención.

\section{La dimensión institucional del derecho y sus principales problemas}

Existen dos datos que hay que poner de relieve: el primero es que Vere no es un agente moral simple; el segundo, que sus decisiones deben estar restringidas por ciertos aspectos que configuran la dimensión institucional del derecho. Sólo a modo de ejemplo vale la pena considerar algunas frases del relato: se trata de hombres que juran "fidelidad" a un soberano y no a la "naturaleza", se trata de "hombres que no son naturales y libres" y que "deben actuar de manera oficial" (Melville 1998, p. 280), regidos por una "conciencia imperial", más que por una "conciencia personal" (p. 281). Estos ejemplos llevan al punto a destacar: la llamada "dimensión institucional del derecho". 9

Se trata de una dimensión que puede ser explicada con base en distintas concepciones (por ejemplo, una emparentada con alguna versión del positivismo jurídico) y con diferente alcance: una que defienda una insularidad o autonomía total del derecho con respecto a una moral crítica, u otra que defienda una insularidad o autonomía parcial del derecho con respecto a una moral crítica. ${ }^{10}$

Esta diversidad de posibilidades de explicación se ejemplifica en el caso de Billy. Por ejemplo, en varios tramos se afirma que "no importando cuán despiadada sea una ley", existe el deber de aplicarla, independientemente de consideraciones de derecho natural (Melville 1998, p. 280).

Esta manera de ver las cosas hace de Vere algo parecido a un juez deferente con el positivismo ideológico (Bobbio 1965), una visión según la cual los jueces, independientemente de cuán injusta o absurda resulte la aplicación de una ley, deben decidir apegados a los términos del derecho. Una visión así del derecho clausura un debate más complejo, tanto más cuanto este derecho remite al "derecho natural". Conforme a esta reconstrucción, la insularidad del derecho respecto de una moralidad crítica se vuelve total.

\footnotetext{
${ }^{9}$ Véanse, por ejemplo, MacCormick y Weinberger 1986, y MacCormick 1998. Más recientemente un reexamen de la dimensión institucional del derecho se halla en Atria 2001, pp. 14-31 y 39-49.

${ }^{10}$ Sobre las dos concepciones de la insularidad del derecho respecto de la moral, téngase en cuenta Atria 2001, pp. 9-14.
} 
Lo explicado anteriormente no debe conducir a pensar que la única manera de dar cuenta de la dimensión institucional del derecho opera en términos del positivismo ideológico. Incluso los seguidores de posiciones más cercanas al iusnaturalismo o más críticas con el positivismo jurídico pueden estar de acuerdo en que esta dimensión del derecho constituye un dato imprescindible del análisis filosófico.

Ahora bien, ¿a qué aspectos remite la idea según la cual el derecho posee una dimensión institucional? Una respuesta canónica puede apoyarse en una especie de núcleo conceptual compartido que trasciende las diferencias de detalle de las concepciones. Según este núcleo, un énfasis en el aspecto institucional del derecho requiere concentrar el análisis en el surgimiento del derecho a partir de "fuentes sociales" (legislación, jurisprudencia, etcétera).

Como se sabe, el gran problema filosófico que enfrenta esta aproximación es el de la "normatividad" del derecho. ${ }^{11}$ Un nuevo nombre para un viejo problema: que interroga a los ciudadanos acerca de por qué deben obedecer al derecho, y a los jueces acerca de por qué, en casos de conflicto externo de obligaciones como el que examino en este trabajo, deben dar preeminencia a la aplicación de normas jurídicas, en detrimento de las normas morales. La respuesta canónica a una pregunta como esta última es que tal "preeminencia" debe explicarse en el elemento de autoridad contenido en el derecho.

Dos son los clásicos problemas que se desprenden de este problema filosófico: primero, si de hechos sociales (o "institucionales") ${ }^{12}$ puede seguirse esta obligación de obediencia; segundo, si el razonamiento práctico es uno o fraccionado. Sin inmiscuirse directamente con una respuesta a estos problemas, es posible caracterizar los aspectos que definen la dimensión institucional del derecho.

El principal aspecto que se ha de subrayar es el elemento de "autoridad" o "pretensión de autoridad" del derecho. Por ejemplo, una posición muy discutida como la de Joseph Raz apoya la pretensión de autoridad en la idea de que las razones jurídicas, o las reglas jurídicas si se quiere, suministran razones excluyentes (de primer y segundo órdenes) y razones independientes de contenido o válidas sólo en virtud de su fuente. ${ }^{13}$

Otros aspectos de la dimensión institucional del derecho que deben ser destacados muestran que cualesquiera que sean las propuestas de "solución" para situaciones de dilema, estas propuestas tienen

${ }^{11}$ Véanse Bayón 1991 y Delgado Pinto 1996.

12 Término acuñado por Anscombe y popularizado por Searle.

${ }^{13}$ Véanse Raz 1990 y 1991. 
que pasar por el filtro o tamiz de la dimensión institucional. Los principales filtros y el modo en que operan son los siguientes.

\subsection{Procedimientos establecidos por el derecho}

En un caso de divorcio, por ejemplo, los jueces no pueden decir, cuando tengan razones empatadas sobre la guarda y custodia de los hijos, "tiramos la moneda y se acabó". Cada uno de los padres podría decir: ¿por qué si mi pretensión es tan justificada como la de la otra persona, le da la tenencia a ella y no a mí? El argumento incluso puede ser sustancial y suponer que la igualdad sustantiva debe reflejarse en una decisión distinta del juez y en la utilización de un mecanismo que no sea el de la moneda.

\subsection{Modalidades de argumentación aceptables}

El juez no puede decir simplemente: "decido así porque se me ocurre o porque me duele el estómago". Un punto de vista sensato sobre el derecho tiende a verlo como una práctica compleja que consiste en "dar y recibir razones". Una práctica de dar y recibir razones se rige por "cánones" de argumentación que determinan criterios de evaluación de las razones. Conforme a estos criterios de evaluación, sería factible determinar en qué grado un argumento es "aceptable" o no lo es. La aceptabilidad es una manera de decir que la argumentación tiene un papel normativo en cuanto que determina qué se puede decir o qué no se puede decir. Los cánones de argumentación de una práctica como la jurídica abrazan tanto argumentos generales (por ejemplo, el modus ponens, la analogía o la reducción al absurdo), cuanto argumentos específicos tales como "argumento a rúbrica", "sedes materiae", etc., así como una batería de argumentos que invocan principios o consecuencias de aplicar normas determinadas. Así, en un caso como el del insumiso penal tratado por Atienza (2002, p. 202), el juez no puede decidir sin dar razones. No puede decir "no aplico la norma penal porque se me ocurre"; tendrá que expresar modalidades de argumentación admisibles. Por ejemplo, si el juez decide excepcionar la aplicación de la norma penal al insumiso puede usar un argumento fundado en principios. Así, puede decir que la articulación de los principios constitucionales de dignidad y libre desarrollo de la personalidad son aplicables al caso, dado que el insumiso es un objetor de conciencia y su objeción goza de una protección constitucional que entra en contradicción con la norma penal. 


\subsection{Piezas o elementos jurídicos}

La dimensión institucional del derecho - en cuanto dimensión regulativa del derecho - no se agota sólo en la existencia de reglas jurídicas de conducta o reglas primarias de obligación. Bajo la dimensión regulativa los juristas también suelen abrazar entidades como los valores o los principios ${ }^{14}$ y directrices $\mathrm{u}$ objetivos colectivos que actúan en el razonamiento jurídico en términos de la operación de razones subyacentes. ${ }^{15}$

Recuérdese que mi tesis era que la dimensión institucional del derecho es un factor importante de análisis. Sin embargo, se trata de un factor a menudo preterido por los filósofos morales que en su discusión sobre los dilemas no distinguen entre dos tipos de agentes. Aunque un agente moral simple tiene que decidir, el agente cualificado institucionalmente tiene que hacerlo sobre un trasfondo de restricciones basadas en todos los aspectos que constituyen la dimensión institucional del derecho señalados.

La falta de atención de los filósofos morales a esta cuestión sólo se explica en la división del trabajo filosófico. Una división así, sin embargo, no está reñida con una visión más "integrada" de la filosofía práctica, en cuanto ésta incluya la filosofía del derecho y la filosofía moral.

Hasta cierto punto parece trivial la tesis que defiende el valor de la dimensión institucional del derecho en la adopción de decisiones; pero lo trivial es sólo apariencia. Hay dos grandes problemas que muestran la relevancia del asunto. El primero atañe a qué tipo de valor tiene esta dimensión en el análisis filosófico. ¿Es un valor "explicativo" o también es un valor "justificatorio"? Es decir, cuando un

${ }^{14}$ Por ejemplo, Atria 2001 y Ruiz Manero 2005, pp. 116-126.

${ }^{15}$ No me apoyaré en una clasificación muy específica de reglas, principios y directrices. Quiero ofrecer una versión de la cuestión lo más amplia y estilizada posible de modo tal que pueda ser discutida por los filósofos morales y no sólo por los del derecho habituados a discutir sobre taxonomías específicas. En esta versión laxa, entiendo por "regla" un enunciado condicional de la forma "si Billy mata a otro, debe ser penado". Siendo una regla jurídica que pretende autoridad en términos razianos, la cuestión en juego es qué papel puedan tener las "razones subyacentes" a las mismas que puedan involucrar principios o directrices. Por "principio" entiendo un enunciado que expresa un valor (derecho a un juicio justo, por ejemplo) y que ofrece razones deontológicas o de corrección en favor de la protección de derechos individuales. Por "directriz" u "objetivo político" entiendo un enunciado que expresa un valor (por ejemplo, la estabilidad del sistema político-jurídico) y que ofrece razones teleológicas o consecuencialistas en favor de objetivos colectivos o agregativos. En caso de que se requieran mayores precisiones, las ofreceré oportunamente. 
filósofo del derecho, como en mi caso, sostiene el valor de esta dimensión, ¿está diciendo que la misma ayuda a explicar el funcionamiento del derecho o también, después de todo, está contribuyendo a justificar una manera especial de aplicar el derecho? No tengo una postura clara sobre este asunto y creo que ello se debe a una cuestión que me sobrepasa: en filosofía práctica, es decir, en una filosofía preocupada por la acción, muchas veces los ingredientes tomados con el propósito de explicar un fenómeno también pueden verse como justificatorios. Aunque esto no impide la disección analítica entre ambos propósitos, la cuestión filosófica de su relación íntima sigue en pie.

El segundo problema mira a los jueces. Los jueces gobiernan su función por un conjunto de valores que no siempre funcionan de manera amistosa. Por ejemplo, un valor importante como es la "independencia judicial" podría determinar que los jueces suprimieran sus "convicciones morales". ${ }^{16}$ Se supone que si quieren ser independientes deben ser la "boca de la ley" y no usar la ley para defender sus propias convicciones cuando discrepan de la misma. Esto hace que la situación de los jueces sea "trágica" en el siguiente sentido. En muchos casos estilo Billy en los que deben actuar, los jueces quieren ser independientes (e imparciales) y al mismo tiempo justos. Y, todo ello, “"aplicando el derecho"! Es posible que parte del problema se pueda ver claramente si separamos dos cuestiones conceptuales independientes: el deber jurídico del juez qua juez respecto de su "responsabilidad moral" por aplicar la norma jurídica.

La claridad no está enemistada, sin embargo, con la posibilidad de asumir que la "tragedia" de los jueces no es sólo que deban sacrificar algo al aplicar la ley. La tragedia tiene un aspecto personal: los jueces muchas veces operan de manera "esquizofrénica" y esto abre una "grieta" en su conciencia. ${ }^{17}$ Este modo de operar se vuelve patente con la oposición que traza el capitán Vere entre un deber jurídico que va en una dirección contraria a sus "escrúpulos morales".

La complejidad de la función judicial se explica, entonces, al considerar que los jueces operan sobre un pluralismo de valores y elecciones que tiene que sacrificar algo. Una complejidad así permite entender por qué no parece raro discutir sobre el alcance y los límites de la "objeción de conciencia" de un ciudadano ordinario y sí parece más extraño hablar de "objeción de conciencia judicial".

${ }^{16}$ Por ejemplo, Aguiló 1997, pp. 71-79.

${ }^{17}$ Recuérdese que Manuel Atienza examina un "dilema moral" enfrentado por un juez en el conocido caso de la "insumisión penal" de un objetor de conciencia, donde el juez, según Atienza, "sigue su conciencia o aplica la ley"; "hace justicia o aplica la ley". Véase Atienza 2002, p. 202. 
Aunque posiblemente extraño, éste es un fenómeno sumergido. Detrás de muchos "apartamientos", e incluso renuncias al cargo, pueden encontrarse objeciones de esta clase.

Es importante atender el hecho de que estas objeciones, que pueden ser más evidentes cuando el juez se somete a un régimen tiránico, no son raras ni imposibles ni erradicables en los casos en que el juez está sometido a un ordenamiento democrático. Es decir: es cierto que, durante el nazismo, si deseaba permanecer en su puesto, el juez debía aplicar las normas jurídicas sin cuestionamiento moral. Quizás al principio sienta asco, pero a la larga es posible que, como Eichmann, haya aplicado las normas sin lamentación. Ahora bien, no es menos cierto que en un orden democrático el juez tenga que tomar decisiones que dejen una obligación relevante a un lado y esto se acompañe eventualmente de pesar.

La "objeción" mostraría que el juez no desea seguir con esa "grieta" que lo divide: un deber jurídico y un escrúpulo moral que son como carros tirados por caballos que corren en sentido contrario.

La existencia de una "grieta" sigue mostrando por qué dos problemas siguen en el centro de las preocupaciones de los filósofos. El primer problema es acerca de cómo concebir el razonamiento jurídico: si como unitario o fragmentado. El segundo problema, conectado con el anterior, es acerca de qué tipo de insularidad o autonomía con respecto a la moral tiene el derecho. Los dos problemas afectan no sólo nuestra comprensión de la relación entre derecho y moral, sino el estatus mismo de ciertos dilemas y el alcance de las posibles salidas a los mismos.

Mi hipótesis es que buena parte de estos problemas ganan en claridad si nos tomamos en serio el papel del razonamiento jurídico. Me parece que parte del enorme valor de On Law and Legal Reasoning de Fernando Atria (2001) se basa en que llama incisivamente la atención sobre la importancia y el alcance del razonamiento jurídico. Es posible percatarse de esta importancia cuando se acepta que la aplicación de una norma general a un caso particular exige algún tipo de razonamiento que conecte la norma con el caso. Por ejemplo, un juez podría usar el razonamiento de la reducción al absurdo como una cuña que impidiera aplicar una norma general que se reputa injusta o absurda para ese caso. ${ }^{18}$

\footnotetext{
${ }^{18}$ Acerca del papel mediador que cumple el razonamiento jurídico interpuesto entre la norma general y el caso particular, véase Atria 2001, especialmente el capítulo 8.
} 
La importancia del razonamiento jurídico no es ajena a Vere y por ello Melville sostiene que el capitán "no era amante de la autoridad por la mera autoridad..." Esto parece indicar que el hecho de ser juez no está en beligerancia con la necesidad de razonar o deliberar a fin de aplicar una norma general a un caso particular. El problema es que los jueces pueden estar "razonando" y aún así aplicar el derecho tal como lo encuentran de primera mano. Esto no era extraño para Kant, quien afirmaba: "Razonad tanto como queráis y sobre lo que queráis, pero obedeced!" 19

En efecto, el llamado "razonamiento jurídico" puede ser controlado por distintas concepciones del derecho. Hasta una concepción ideológica del positivismo jurídico podría justificar la combinación de cierto "razonamiento" con una aplicación de la ley "por más despiadada que ésta sea", como alega Vere. ${ }^{20}$

De las numerosas implicaciones que pueda tener lo señalado, solamente quiero detenerme en aquellas que tengan pertinencia directa en el examen de las soluciones que los filósofos del derecho y de la moral darían a un caso como el de Billy.

\section{Las soluciones de los filósofos del derecho: tres respuestas}

En lo que sigue, me propongo detenerme en tres respuestas a un caso como el de Billy. ${ }^{21}$ Dos de las respuestas se mantienen dentro del derecho, mientras que la última busca la solución fuera del mismo. Llamaré a estas respuestas "respuesta jurídica simple", "respuesta jurídica compleja" y "respuesta moral". En la presentación de estas respuestas evitaré identificarlas con algún "rótulo" y con

${ }^{19}$ Kant 2004, p. 39.

${ }^{20}$ Melville 1998, p. 280.

${ }^{21}$ En vez de dar respuestas subjetivistas y decisionistas a los dilemas como las preconizadas por los Critical Legal Studies (como Duncan Kennedy, 1986, pp. 518562), el "común denominador" de las tres respuestas que examinaré se define por la pretensión de "objetividad". En el nivel de las respuestas jurídicas simples, esta objetividad es parasitaria de interpretaciones literales fiables; en éstas, el criterio de corrección u objetividad está dado por reglas cuyo contenido es cognoscible sin mayor dificultad y en las que el resultado de la interpretación goza de amplio acuerdo. En el nivel de las respuestas jurídicas complejas, esta objetividad es parasitaria de una interpretación más profunda de razones subyacentes al tenor literal de las reglas, cuyo criterio de corrección u objetividad está dado por el derecho concebido como una práctica compleja regida por cánones de argumentación normativos compartidos. Por último, en el nivel de las respuestas morales, su objetividad se puede reconstruir, por ejemplo, con relación a una "práctica virtuosa", a "principios morales universales", "hechos normativos" independientes de las convenciones, etcétera. 
algún "nombre conocido" de la filosofía jurídica. ${ }^{22}$ Una discusión en términos de rótulos y nombres no lleva más que a confusión. Por ejemplo, lo que denomino respuesta jurídica "compleja", ¿está más cerca de lo que un filósofo dworkiniano (Dworkin 1996) defendería y, en consecuencia, sería antipositivista? ¿O estaría más cerca de lo que hoy se denomina positivismo ético, al estilo de argumentos defendidos por un filósofo como Atria? Los rótulos y los nombres pueden convertirse en una frivolidad que distrae; por consiguiente, no será necesario preocuparse por ellos.

\subsection{La respuesta jurídica simple y sus problemas}

Una primera respuesta al caso de Billy puede ser construida con base en el derecho. Esta respuesta — jurídica - puede ser "simple" o "compleja".

Denomino "simple" a una respuesta que no requiere demasiado esfuerzo hermenéutico, porque se trata de una respuesta apegada al texto "literal" de las reglas identificadas como aplicables; por ejemplo, en este supuesto, apegada a la regla del código de guerra que sanciona el homicidio con pena capital sin distinguir entre presencia o ausencia de intencionalidad en la acción.

El apego al tenor literal que mantiene el intérprete lo vuelve ciego con respecto a otras consideraciones sustanciales subyacentes a las reglas; por ejemplo, consideraciones que apuntaran a distinguir casos de homicidio con intención de casos de homicidio sin intención a efectos de discernir reproches diferentes.

Generalmente, este tipo de respuesta presupone que el derecho se agota en las reglas y que éstas operan como excluyentes de otras consideraciones sustanciales. Estas consideraciones sustanciales pueden ser de dos tipos diversos: o bien consideraciones sustanciales jurídicas que se encuentren implícitas o subyacentes; o bien consideraciones sustanciales extrajurídicas, cuya apelación requiera salir del derecho hacia otro dominio, por ejemplo, el de una moral crítica.

\footnotetext{
${ }^{22}$ También evitaré la conocida discusión acerca de si hay una suerte de "orden" conceptual o evaluativo en estas respuestas. Quizás el orden en que presentaré las tres respuestas refleje un modo "natural" muy extendido entre los teóricos del derecho de presentar las cosas, que sugeriría que la prioridad en primera medida la tiene la respuesta simple, seguida de la compleja y, en última instancia, continuada por la respuesta moral. Seguiré este orden natural, pero sin presuponer una defensa explícita de algo así como un orden conceptual o evaluativo. Ello me llevaría más lejos de lo que pretendo aquí, dada la limitación que yo mismo he planteado para el análisis.
} 
¿Qué ocurre cuando la aplicación de la regla se muestra absurda o injusta? Adviértase que, en el caso de Billy, Vere entiende que la "falta de intención" debería ser una propiedad relevante. Una versión que agota el derecho en reglas identificadas sólo por su tenor literal, y que asume estas reglas como excluyentes de consideraciones sustantivas, hace de la "relevancia" de la intención una cuestión de índole valorativa ${ }^{23}$ que, en vez de asumir carácter jurídico, estaría relegada al ámbito extrajurídico.

El producto de esta manera de interpretar el derecho explica una suerte de obediencia inderrotable al derecho. Esto es así porque ninguna consideración sustantiva tiene la virtud de bloquear la solución prevista: condenar a pena de muerte a Billy. No siempre queda claro que sea solamente una interpretación literal de las reglas la que conduzca a este refuerzo —ideológico — de la obediencia al derecho. Téngase en cuenta que, en el caso de Billy, Vere realiza también un razonamiento consecuencialista que mide cuáles podrían ser las probables consecuencias de no aplicar, la ley marcial (Melville 1998, p. 283), independientemente de cuán despiadada sea. Su conclusión es que hacer de la "falta de intención" de Billy una "excepción" produciría una afectación en la "estabilidad general del sistema". La idea de "estabilidad general del sistema" está presente en la mentalidad jurídica ordinaria. Los juristas, a menudo, suelen articular esta idea en la operatoria de lo que Atienza y Ruiz Manero denominan "principios institucionales". Según estos dos filósofos, muchas veces los principios jurídicos en sentido estricto sustantivos, esto es, aquellos que refieren a razones de corrección sustanciales conectadas con estados de cosas a los que se atribuye valor último, ${ }^{24}$ pueden ceder frente a principios institucionales en sentido estricto ${ }^{25}$ principios que, conforme a los autores citados, explican y justifican la necesidad de estabilidad del sistema jurídico. Esta reconstrucción tiene la ventaja, según Atienza y Ruiz Manero, de explicar instituciones como las de los "estados de excepción" y de "sitio" que implican la justificación de la preservación de la estabilidad del sistema jurídico como un todo y, dado este valor, se justifica el "sacrificio" de valores sustantivos (2001, pp. 122-129).

Que Vere interprete el derecho de la manera indicada tiene su explicación en una interpretación previa que hace de su posición ins-

${ }^{23}$ Algo similar a la producción de una "laguna axiológica". Sobre el conocido concepto de laguna axiológica véase el clásico Alchourrón y Bulygin 1987. Para una discusión más reciente del concepto, véase Rodríguez 1999, pp. 349-369.

${ }^{24}$ Tales como los "derechos individuales".

${ }^{25}$ Véase Atienza y Ruiz Manero 2001, pp. 122-129. 
titucional. Él sostiene que los que están en su posición "no actúan como agentes libres y naturales", sino como agentes que han jurado fidelidad a un soberano. La afirmación de Vere puede comprenderse combinando dos ideas que ya he presentado: por un lado, que la dimensión institucional del derecho actúa limitando las decisiones judiciales; por el otro, la idea de que los jueces son agentes cualificados institucionalmente, motivo por el cual ya no son libres como un agente natural, es decir, como un agente no institucionalizado por el derecho.

El punto es que el estatus institucional que detenta un agente, en este caso, el estatus de ser "juez", restringe el campo de las razones que tiene permitido usar. En buena medida, esto es lo que Pablo Navarro tiene en mente cuando distingue "caso individual" de "caso judicial", donde este último conecta con normas que un juez, por su posición institucional, debe emplear (Navarro 2005, p. 93).

Robert Brandom ha entrevisto claramente este aspecto. El ejemplo de Brandom es el del "empleado de banca" que, por este hecho, o por esta razón, "tiene el deber" de llevar corbata. Según Brandom, el estatus institucional de ser "empleado de banca" determina este deber. En otras palabras, cierto estatus social genera un compromiso en el agente de guiarse por las razones asociadas a dicho estatus, además del hecho de habilitar al agente para que actúe en el sentido indicado, o de permitir que lo haga (Brandom 2002, p. 111).

Al igual que un empleado de banca, el capitán Vere debe aplicar la ley marcial. De modo que la interpretación que efectúa está iluminada por el tipo de posición institucional que él ocupa.

¿Pero acaso lo anterior lleva a concluir que la dimensión institucional del derecho sólo puede ser interpretada del modo restringido que subyace a la respuesta jurídica simple? ¿Hay otros modos de comprender la dimensión institucional del derecho? Mi respuesta es afirmativa y se basa en el modelo de una respuesta jurídica compleja.

\subsection{La respuesta jurídica compleja y sus problemas}

Denomino "compleja" a una respuesta que presupone dos aspectos: por un lado, mantiene una visión más "holística" de la interpretación jurídica; por el otro, no se agota en captar el tenor literal de reglas asumidas como excluyentes, sino que también abraza razones sustantivas subyacentes jurídicamente relevantes. Explico brevemente los dos aspectos de esta complejidad.

Una visión holista de la interpretación jurídica determina que la respuesta jurídica a un problema requiera una tarea delicada de iden- 
tificación del sistema aplicable. No siempre la mejor respuesta jurídica a un caso se encuentra en un sector del ordenamiento jurídico. En ocasiones se requiere una inspección más profunda. Esta inspección puede llevar a un resultado contrario al que se observa en el caso de Billy. Por ejemplo, Vere no tenía quizás que aplicar la Ley de Amotinamiento, dado que ésta era una medida temporal votada por el parlamento británico en 1689, y que no obligaba a la Marina, la cual se regía por otra ley de 1749 completamente diferente. ${ }^{26} \mathrm{Si}$ en esta ley la "falta de intención" tenía un tratamiento explícito, Vere no hubiese enfrentado un dilema. Esto no es extraño. Téngase en cuenta que la categoría de dilema tiene un rasgo "relacional": los dilemas son "relativos" a un sistema, motivo por el cual es tan importante identificar el sistema en el que surge el dilema. Conforme a lo expuesto, se podría alegar que Vere realiza una mala tarea de orfebrería a la hora de identificar el sistema normativo aplicable.

El otro aspecto de la complejidad consiste en afirmar que las respuestas del derecho siguen siendo tales, aunque no actúen por medio de reglas asumidas como excluyentes de consideraciones legalmente relevantes.

La idea que intento transmitir es la siguiente. Asumo que el derecho tiene una dimensión regulativa que no actúa sólo en el nivel (1) de las reglas, sino también en el nivel (2) de lo que se podría llamar "razones subyacentes", "principios implícitos" que no satisfacen de manera evidente y directa una prueba de pedigree del sistema jurídico, "valoraciones de la finalidad o función de las reglas", etc. Esta idea no es nueva; se encuentra en la literatura iusfilosófica de diversas maneras y atraviesa la obra de diferentes filósofos del derecho.

Focalizar la dimensión regulativa del derecho en dos niveles repercute en la manera de concebir la dimensión institucional del derecho. No existe una necesidad analítica de enfocar esta dimensión institucional restringiéndose al nivel 1 ; resulta factible incluir también el nivel 2. Este nivel 2 explica por qué no es inusual que los juristas en sectores como el derecho penal articulen, en ocasiones, distinciones implícitas que lleven a justificar la disminución de reproche para cierto comportamiento, por ejemplo, el de Billy. Es decir, los penalistas suelen interpretar el código penal no sólo en términos del nivel 1, sino también del nivel 2, articulando entidades como los principios o razones subyacentes y ejercitando cierta tarea de balance; por ejemplo, de las razones inmediatas que surgen de guiarse por el tenor literal de las reglas junto a las razones subyacentes suministradas por

${ }^{26}$ Véase Melville 1998, p. 282, n. 44. 
ciertos principios que permiten identificar excepciones implícitas que deberían ser jurídicamente atendibles. ${ }^{27}$

Lo que estoy insinuando ilustra la existencia de dos explicaciones diferentes de la dimensión institucional del derecho y el alcance del razonamiento jurídico. La primera es una explicación que, para decirlo un tanto metafóricamente, se agota en las fuentes, entendiendo por "fuentes" sólo un conjunto de reglas excluyentes identificadas por su tenor literal. La segunda explicación enfoca la dimensión institucional más bien en términos de una "práctica" que incluye un razonamiento jurídico de mayor alcance, el cual se articula en razones subyacentes consideradas jurídicamente relevantes.

Las dos explicaciones presuponen dos concepciones diferentes de los "límites del derecho". En la primera, la roca contra la que choca la pala es un conjunto de reglas excluyentes identificadas por su tenor literal. En la otra, esta roca está más profundamente ubicada y exige articular un razonamiento jurídico de mayor alcance.

Si se conectan estas explicaciones con la idea de "insularidad" o "autonomía" del derecho, cabría apuntar lo siguiente. Mientras que la primera explicación determina una insularidad total del derecho con respecto a consideraciones sustantivas (tanto jurídicas como extrajurídicas), la segunda explicación mantiene una insularidad parcial, al menos para lo que refiere a las razones subyacentes de carácter jurídico. La insularidad total hace que el planteamiento de ciertas razones sustantivas parezca "fuera de lugar". En un sentido importante, la insularidad total se explica en una analogía subyacente entre las reglas jurídicas —asumidas como excluyentes - y las reglas de un "juego" como el ajedrez donde las razones sustantivas no parecen tener cabida. ${ }^{28}$ La mencionada analogía agota el aspecto "formal" de las reglas en su carácter "excluyente". Sin embargo, no hay una forma única de entender la "formalidad" del derecho. La formalidad del derecho no tiene por qué actuar "a todo o nada"; puede actuar de manera "gradual" dando cabida, en casos como el de Billy, a consideraciones sustantivas introducidas con las armas del razonamiento jurídico. ${ }^{29} \mathrm{Al}$ respecto, hay que tener en cuenta que analizar la dimensión institucional del derecho en términos de una práctica presupone que el razonamiento jurídico no puede operar en forma

\footnotetext{
${ }^{27}$ Ésta es la línea de pensamiento que siguen autores como Roxin cuando reconstruye la cuestión de las causas de justificación implícitas en términos de principios que deben ser ponderados por los jueces. Un análisis adecuado de la cuestión se encuentra en Moreso 2001, p. 539.

${ }^{28}$ Sobre esto, véase Atria 2001, especialmente el capítulo 1.

${ }^{29}$ Véase Atria 2001, especialmente los capítulos 7 y 8.
} 
caprichosa. Tal como he sugerido, los juristas operan con un razonamiento regimentado por "cánones" que delimitan el campo de las razones o los argumentos permitidos.

La explicación de la dimensión institucional del derecho en términos de una práctica invita a realizar tres consideraciones. La primera es que esta explicación asume que los límites del derecho no se agotan en las reglas. Esta afirmación tiene una consecuencia notable en el problema de la "indeterminación" del derecho que ocasionarían los dilemas. Según esta explicación, verificada una indeterminación en cierto nivel del derecho (el 1), no es menester acudir a una moral crítica. Antes bien, resulta factible bucear en un nivel (2) más profundo del derecho. En suma: ante una indeterminación en un nivel del derecho, no es necesario ir a una moralidad crítica, sino que es posible articular algo así como un "derecho crítico". 30

La idea, más allá de la exégesis puntual de un autor, es que el nivel 2 del derecho permite actuar como "correctivo" o "crítico" del razonamiento jurídico efectuado sólo sobre la base del nivel 1. En el fondo, se supone que esta crítica es correctiva en un sentido positivo en la medida en que ese derecho profundo tenga algún fundamento de moralidad $^{31}$ o justicia inmanente. ${ }^{32}$ La idea también está en Brandom. Según él, el carácter institucionalizado de una práctica no cancela una actitud crítica de los participantes que permita revisar sus compromisos normativos (Brandom 2002, p. 237).

La segunda consideración es que focalizar la dimensión institucional del derecho en términos de una práctica supone tácitamente la existencia de un consenso más o menos generalizado sobre qué razones subyacentes son atendibles y qué argumentos jurídicos son aceptables. Aunque este consenso no elimina completamente ciertos

\footnotetext{
${ }^{30}$ Por ejemplo, al estilo de The Idea of Private Law, de Ernest Weinrib (1995). Mi propósito no es identificarme con Weinrib, sino mostrar que su idea de una racionalidad crítica inmanente al derecho, en su caso al derecho privado, presupone un tipo de idea semejante a la que se encuentra implicada en mi argumentación.

${ }^{31}$ De moralidad o justicia en cuanto la práctica jurídica presuponga valores morales compartidos; por ejemplo, en torno al tipo de reproche que cabe para una clase de caso como el de Billy.

${ }^{32}$ Deliberadamente uso estas expresiones como sinónimas y con bastante amplitud. La idea es que si las respuestas satisfacen estas pruebas internas del derecho, están justificadas. Deseo aclarar que estas pruebas operan como "correctivos" y, a diferencia del positivismo ideológico, pueden contribuir a derrotar la obediencia a una regla que se entienda que no los satisface. Sin embargo, como se verá enseguida, estas respuestas que pueden considerarse "justificadas" podrían ser vistas como inaceptables, inmorales, etc., desde una perspectiva moral crítica externa al derecho.
} 
desacuerdos residuales, se podría decir que restringe la posibilidad del "todo vale" argumentativo.

La tercera consideración es que esta explicación de la dimensión institucional es conservatista. ${ }^{33}$ Es decir, bien articulada permite conservar el hecho de que las respuestas sigan siendo jurídicas. En la medida en que las respuestas jurídicas satisfagan un ideal de moralidad o justicia subyacente a las reglas jurídicas, el conservatismo parece sensato y no constituye una second best, sino una first best way para tratar la cuestión.

En mi caso, me inclino a favorecer tentativamente este tipo de respuestas a los dilemas. Precisamente, los dilemas son situaciones harto complicadas que en general no pueden ser resueltas apelando a respuestas simples. Incluso pienso que en un caso como el de Billy, una respuesta jurídica compleja podría resolver sustancialmente el dilema sin sacrificar nada o, a lo sumo, sin sacrificar de manera significativa nada. Sin embargo, nada está garantizado. En otros dilemas quizás no podría darse una resolución sin sacrificio.

En este caso, mi inclinación es tentativa, porque no siempre el conservatismo es una vía plausible. Resulta factible que existan desacuerdos importantes en la práctica acerca de la solución de un caso. Incluso puede ser que haya un consenso alto sobre la solución del caso, pero ésta puede ser juzgada como irracional, ilegítima o injusta desde el punto de vista de una moral crítica.

Una moral crítica, a su vez, puede ser reconstruida a partir de opciones muy diversas: por ejemplo, una que la haga depender de "hechos normativos" que "trascienden" o son "independientes" de la práctica, o bien otra que la haga depender de ciertos "principios racionales universales".

Sea cual fuere la reconstrucción adoptada, la moralidad crítica viene a actuar en sentido contrario al conservatismo de la respuesta jurídica compleja. Su sentido "correctivo" no apunta a conservar la práctica bajo el mejor aspecto posible. Antes bien, apunta a modificar o cambiar la práctica o parte de ella. Cuando esto ocurre, la respuesta ya no es jurídica — compleja_, sino moral, lo cual me lleva al siguiente punto.

\footnotetext{
${ }^{33}$ En el sentido transmitido por la famosa metáfora de Neurath acerca del barco que debe ser reparado en el mar. La idea intuitiva es que no podemos cambiar radicalmente los elementos básicos que constituyen nuestra práctica; más bien reajustamos algunos elementos a efectos de actualizar la práctica, pero sin alterar su identidad básica.
} 
3.3. La respuesta moral y sus problemas

Habitualmente, cuando los juristas admiten la necesidad de una respuesta moral, esta respuesta suele estar vinculada a la invocación de principios de derecho natural, tal como surge en la apelación hecha por Vere en el caso de Billy.

La apelación de Vere presupone que la respuesta jurídica compleja no ha sido capaz de habilitar una distinción de casos de homicidio (con o sin intención) y de niveles de reproche diferentes, y mucho menos la respuesta jurídica simple. Ello explicaría el recurso a una respuesta moral en la expectativa de que quizás ella sí permitiría trazar las distinciones mencionadas.

Ahora bien, existen desacuerdos en el interior de la respuesta moral. Los desacuerdos pueden afectar dos aspectos que hay que distinguir: por un lado, cuál pueda ser el tipo de solución que corresponda dar al caso, ${ }^{34}$ por el otro, respecto del alcance de estas soluciones.

En lo que sigue muestro brevemente cómo se debate el tipo de solución y su alcance bajo una ética de la virtud y una ética kantiana.

4. Las soluciones de los filósofos morales: ética de la virtud frente a ética kantiana

El capitán Vere había sostenido que en el caso de Billy no se podía actuar ni como "casuistas" ni como "moralistas" (Melville 1998, p. 280). Los casuistas, sean jurídicos o morales, acentúan el valor de cada caso particular, mientras que lo que Vere llama "moralistas" podría estar más cerca de aquellos que aspiran a una generalización de la solución para ciertos casos. Suponiendo que Vere esté equivocado y el caso de Billy requiera una respuesta moral, ella no parece fácilmente asequible pues podría haber desacuerdos como los ya referidos.

Para simplificar mi análisis voy a presentar este desacuerdo filosófico moral en términos de dos teorías éticas presuntamente rivales: una ética de la virtud y una ética kantiana. Habitualmente tiende a verse una diferencia entre ambas teorías éticas no sólo respecto de qué "entidades" son aptas para integrar la "respuesta" ("virtudes" frente a "principios morales universales"), sino que, además, la diferencia suele medirse respecto del "alcance" de estas respuestas. En

\footnotetext{
${ }^{34}$ Esto es, si la solución del caso se obtendrá, por ejemplo, deduciendo de un principio moral universal una respuesta concreta para el caso de Billy o si esta respuesta se obtendrá mediante la captación perceptual de un agente virtuoso que estará más atento a una solución que calce con el caso, que a una solución que sea deducible de un principio universal.
} 
lo que concierne a esto último, tiende a verse en la ética de la virtud un compromiso con argumentos particularistas, ${ }^{35}$ en tanto que en las éticas de tipo kantiano un compromiso con argumentos generalistas o universalistas. ${ }^{36}$ Dicho en otros términos: mientras que la ética de la virtud tendría una impronta "casuista", la ética kantiana tendría una impronta "codificada", esto es, referida a un conjunto cognoscible y estable de principios y/o reglas de aplicación universal.

La ética de la virtud se construye en torno a los conceptos de "virtud" y "persona virtuosa". Según John McDowell, la "virtud" "es una disposición (quizás una clase especialmente racional de autoconciencia) a comportarse correctamente" (1998, p. 50).

La suposición común que subyace a una ética de la virtud es que un hombre virtuoso puede salir airoso de situaciones de dilema. ${ }^{37}$ Por ejemplo, una virtud "clave" es la entronizada por Aristóteles como centro de la deliberación práctica: la phronesis o "prudencia". Se supone que la prudencia es una especie de facultad de juzgar particulares sin el afán de identificar principios universales. Desde esta perspectiva, resolver problemas morales no requiere la "aplicación de principios universales, sino ser cierta clase de persona: alguien que ve las situaciones en cierto sentido distintivo". ${ }^{38}$ Así como en la ética kantiana tienen prioridad normativa los principios universales, en la

\footnotetext{
${ }^{35}$ Para una crítica a la vinculación de Aristóteles con el particularismo fuerte, véase Irwin 2000, p. 104.

${ }^{36}$ Estoy planteando la distinción entre particularismo y generalismo o universalismo de un modo muy general. Dados los propósitos de mi trabajo, no se requieren aquí muchas otras distinciones relevantes.

${ }^{37}$ Lo interesante de la idea de virtud es que parece una categoría de cierta fecundidad en cuestiones como la de los dilemas, que ponen de manifiesto los "límites" de la racionalidad práctica. Precisamente, como ha señalado Atienza (2003, p. 129), autores como Neil MacCormick, en particular en su obra Legal Reasoning and Legal Theory (1978), han sostenido que cuando la razón muestra sus límites es posible activar el juego de virtudes como la "altura de miras", la "paciencia" o "la valentía". Sin embargo, este juego de las virtudes no se encuentra exento de problemas. Existen dos problemas muy conocidos. El primer problema es determinar si las virtudes pueden formar un grupo coherente. La cuestión es que a veces la satisfacción de una virtud puede implicar el sacrificio de otras virtudes relevantes. (Sobre esto, véase Crisp 2000, p. 104.) El segundo problema, para quien no profesa una fe aristotélica en la infalibilidad de la deliberación práctica, consiste en saber si la aplicación de una virtud es correcta. Por ejemplo, si se toma en cuenta la "valentía" en un caso como el de Billy, ¿qué implicaría esta virtud? ¿Cuándo un juez es "valiente"? ¿Es valiente cuando aplica pese a todo una ley que estima injusta, o es valiente cuando tiene el coraje de no aplicar tal ley? Como se advierte, el segundo problema tiene un aire "kripkeano" y apunta a la ya consabida cuestión del "seguimiento de reglas".

${ }^{38}$ McDowell 1998, p. 73. Las cursivas son mías.
} 
ética de la virtud pareciera ser que la prioridad la tiene lo "particular" y la capacidad del agente de percibir las peculiaridades "salientes" de lo particular o, en palabras de Vere, de captar la genuina excepcionalidad del caso de Billy Budd. Además, la percepción de la genuina excepcionalidad de un caso puede estar atada al descubrimiento del agente de aspectos de su propia personalidad.

Dicho énfasis en lo "particular" condujo a Peter Winch a señalar que, en cierto tipo de casos de conflicto moral, la tesis de la "universalizabilidad" del juicio moral carecía de "fuerza lógica". La idea de Winch es que la persona que siente la fuerza de demandas moralmente conflictivas dentro de sí y finalmente decide "esto es lo que debo hacer" no está lógicamente comprometida a aceptar como corolario el siguiente juicio: "y en situaciones como éstas todos los demás deben hacer lo mismo" (Winch 1972, p. 161). Precisamente, como ejemplo de afirmaciones normativas del tipo "esto es lo que debo hacer" sin la mencionada "fuerza lógica", Winch piensa en la situación en que se encuentra el capitán Vere en Billy Budd. La idea de Winch es que otra persona que se hallara en la situación de Vere podría llegar a la conclusión opuesta.

El argumento de Winch parece asociarse al tipo de argumentos que utilizan autores como McDowell, en el sentido de que, en situaciones morales complejas, la gente toma decisiones en función de la captación de aspectos salientes de ese caso y no con base en una constelación de principios universales. Esto podría revestir la siguiente variante: una persona que se encontrara en la posición de Vere decidiría en función de sus disposiciones subjetivas (que puede descubrir al intentar tomar una decisión) y no de la existencia de principios ya codificados que permitan subsumir el caso.

Como se sabe, el razonamiento de Winch fue reconstruido desde varios flancos. Según Kolenda, es cierto que Vere parece estar envuelto en un dilema moral desde el punto de vista de que percibe su tarea como oficial de la Marina en términos morales; desde esta perspectiva, "percibe un conflicto moral entre su obligación de obedecer las leyes navales y lo que podría llamarse su "conciencia privada" "39

Sin embargo, Kolenda sostiene que la decisión de Vere no reposa simplemente en el descubrimiento de algún aspecto de sí mismo, sino también en el "rol" que él tiene que cumplir en el destino de su comunidad moral (Kolenda 1975, p. 461). La idea de "rol dentro de su

\footnotetext{
${ }^{39}$ Kolenda 1975, p. 461. Vere refiere a esto usando las expresiones "conciencia personal" y "escrúpulos morales".
}

Crítica, vol. 39, no. 116 (agosto 2007) 
comunidad moral" no es muy distinta de la idea de posición o rol institucional que manejo; un rol que mira aspectos - institucionalespropios del derecho que en un sentido lato conforman lo que, en clave fulleriana, se suele llamar "moralidad interna" del derecho.

De cualquier modo, téngase en cuenta que el conflicto moral de Vere tiene su raíz en el siguiente hecho: aunque Billy no es inocente del delito de homicidio imprudente o preterintencional, sea como fuere que se reconstruyera su caso, sí es "inocente" de un homicidio intencional, en el sentido de que mató a Claggart sin tener la intención de hacerlo. Además de este hecho hay que destacar que Vere siente evidente simpatía por Billy y aversión por Claggart. Son estos "sentimientos" los que - reconoce Vere- podrían debilitar la decisión; de aquí surge una discrepancia moral entre la "rigidez" de las leyes navales en que Vere basa su decisión y la necesidad de "modificarlas" considerando la "falta de intención" de matar en el caso de Billy.

El argumento de Kolenda es que lo que en la elaboración de su decisión Vere descubre no es la mera simpatía o identificación con las virtudes de Billy; también descubre que las circunstancias del caso le exigen obediencia hacia las leyes navales que son una articulación de ciertos objetivos morales de la comunidad. Es por ello que, observa Kolenda, la decisión de Vere no es arbitraria (1975, p. 462).

Según Kolenda, Vere se encuentra en una situación muy parecida a la que vivía Sócrates cuando se le ofreció escapar de la prisión que lo retenía. Desde que Vere acepta los objetivos morales de la comunidad, él tiene que aceptar con contrito silencio el veredicto de las leyes navales, tal como Sócrates lo hizo en su imaginaria confrontación con las leyes atenienses (Kolenda 1975, p. 462). Sin embargo, este "contrito silencio" no es producto de una necesidad analítica sino, antes bien, de una concepción de la dimensión institucional del derecho y el razonamiento jurídico gobernada por algo parecido a lo que se conoce como positivismo ideológico. Vere, al igual que Sócrates, es un agente deferente al positivismo jurídico ideológico.

Ahora bien, la principal crítica de Kolenda a Winch es que la conclusión de la decisión de Vere, si es moral, tiene que valer no sólo para él, sino para cualquier otro capitán (Kolenda 1975, p. 464). Si la decisión de Vere implica una auténtica "resolución moral", ésta tiene que ser universalizable y no meramente subjetiva, a menos que la idea de deber se torne "moralmente vacía" (1975, p. 465).

Joseph Raz también se ha ocupado del análisis del caso Billy Budd hecho por Peter Winch. Acertadamente, Raz encuentra que en el 
razonamiento de Winch existe la distinción entre juicios "morales" desde la perspectiva de la "primera" y la "tercera" personas. Los juicios acerca de si una acción $x$ es correcta o no parecen referidos a la perspectiva de la primera persona dado que, en la "misma situación", $x$ es correcto para mí, pero puede ser incorrecto para ti (Raz 2000, p. 71).

Sostiene Raz que el tipo de caso que testifica Billy Budd es aquel donde, juzgando las cosas impersonalmente, "no hay respuesta a la cuestión de cuál conjunto de consideraciones debe prevalecer". Ello es así por cuanto las consideraciones conflictivas son "inconmensurables" (Raz 2000, p. 72).

La reconstrucción de Raz pondría de manifiesto que decir que " $x$ " es correcto para mí e incorrecto para ti presupondría la aceptación de que las inclinaciones personales son parte de las razones (personales) para decidir. La idea es que es la "inocencia" de Billy — en cuanto a un "homicidio intencional o doloso" - y no la "simpatía personal por él” que siente Vere lo que operaría como una razón inconmensurable con las razones expresadas por las leyes navales. Es decir, la idea es que la acción $x$ puede ser correcta para un agente y no para otro debido a que la razón está indeterminada, no guía hacia una respuesta justificada, pues las alternativas son inconmensurables. ${ }^{40}$ Dado que las cosas son así, es posible explicar la operatividad de las sensibilidades morales de quienes están envueltos en el dilema. Serán estas sensibilidades —ya no la razón- las que intervendrán en la elección de la alternativa. Desde este punto de vista, lo que quiere mostrar Winch - explica Raz - es que, en casos como los que enfrentan agentes como Vere, el privilegio lo tiene la perspectiva de la primera persona y no la de la tercera, que es la que permite distinguir lo correcto de lo incorrecto (2000, p. 75).

Sostener en el derecho la "perspectiva de la primera persona" resulta altamente problemático. Si la dimensión institucional del derecho es atendida, no es tan sencillo aceptar que las razones de Vere, qua juez, sean personales sin más; aun cuando estas razones sean asumidas como "correctas" desde un punto de vista moral determinado. La dimensión institucional del derecho orbita sobre valores como la seguridad jurídica y parte de ella descansa en la exigencia bastante compartida de que las razones que aduzcan los jueces, aun si tienen una génesis y una explicación en características de la personalidad de los mismos, se ajusten a pautas públicamente aceptadas y sean susceptibles de generalización. Por supuesto, esta exigencia no

\footnotetext{
${ }^{40}$ Véase Raz 2000, p. 74 y nota 37.
} 
elimina per se el problema del particularismo y eventual subjetivismo de las decisiones judiciales.

\section{Recapitulación de algunos aspectos}

Mediante el ejemplo de Billy Budd, en este artículo me he ocupado de un dilema que puede tratarse en términos de un conflicto externo de obligaciones. Este conflicto está encarnado en el tipo de dilema presupuesto en la decisión que tiene que adoptar el capitán Vere.

Al recurrir a ese ejemplo, he querido introducir, en la reconstrucción conceptual de los dilemas, un factor de análisis descuidado en la discusión filosófico moral estándar como la que he presentado en la sección anterior. Me refiero a la dimensión "institucional" del derecho. Cuando digo "descuidado" introduzco un matiz. No se trata de un descuido injustificado, sino exigido por razones de restricción en el análisis hecho por los filósofos morales, y de división de tareas con respecto a los filósofos del derecho. Mi afirmación más bien intenta destacar la necesidad de una visión más integrada de los dilemas que conduzca a un puente más explícito entre filosofía moral y filosofía jurídica.

Mi idea es la siguiente: el examen de los dilemas tiene que tener un aspecto contextual que permita captar elementos analíticos interesantes. Estos aspectos surgen cuando se consideran las diferencias contextuales existentes entre un dominio moral no institucionalizado y otro institucionalizado, como el del derecho. La distinción de contextos es paralela a la distinción de agentes: los agentes morales no cualificados institucionalmente no tienen los mismos apremios que los que sí lo están.

Mi argumento acerca de la necesidad de dar cuenta del contexto institucional del derecho en cuanto sean jueces los que se enfrenten a dilemas se basó en una toma de partido respecto de cuál concepción de esta dimensión me parecía más defendible. Sostuve que tal concepción es la que se expresa en lo que llamé la "respuesta jurídica compleja". Mi defensa de este tipo de respuestas, sin embargo, no supone una adhesión fanática. Es posible que en ocasiones se requiera una respuesta a un caso que se salga del derecho.

Queda pendiente de análisis si esta obligación de los jueces de adoptar decisiones —que además estén "fundamentadas" — puede cumplirse y con qué alcance. Los dilemas morales o jurídicos parecen plantear algún tipo de "indeterminación" del derecho, al menos en cierta etapa de la interpretación y la aplicación jurídicas. Esta inde- 
terminación exige pensar en el alcance de la obligación de los jueces de decidir casos de manera fundada.

En este punto, las respuestas de los teóricos jurídicos contemporáneos son variadas y en muchas ocasiones discordantes. Muy brevemente y a modo de ejemplo, recuérdense las diferentes visiones que sobre la existencia de lagunas normativas y obligaciones de los jueces manejan autores como Atria y Ruiz Manero, por un lado, y Alchourrón y Bulygin, por el otro. Los primeros defienden la idea según la cual los jueces tienen la obligación "específica" de "rechazar la demanda"; ${ }^{41}$ mientras que Alchourrón y Bulygin creen que, en estos casos de laguna, sólo existe una obligación "genérica" de decidir, pero los jueces son "discrecionales" respecto de si rechazan la demanda o no. ${ }^{42}$

Ahora bien, el análisis de cuáles pueden ser las obligaciones de los jueces - y sus posibilidades - en decisiones sobre dilemas es un tema que, por su complejidad e importancia, requerirá un futuro trabajo. ${ }^{43}$

\section{BIBLIOGRAFÍA}

Aguiló, J., 1997, “Independencia e imparcialidad de los jueces y argumentación jurídica", Isonomía. Revista de teoría y filosofía del derecho, no. 6, pp. 71-79.

Alchourrón, C. y E. Bulygin, 1987, Introducción a la metodología de las ciencias jurídicas y sociales, Astrea, Buenos Aires.

Atienza, M., 2003, Las razones del derecho. Teoría de la argumentación jurídica, Instituto de Investigaciones Jurídicas-UnAM, México.

—_ 2002, "Los límites de la interpretación constitucional", en Rodolfo Vázquez (comp.), Interpretación jurídica y decisión judicial, Fontamara, México.

${ }^{41}$ En casos civiles. En los criminales, la obligación específica sería "absolver" al acusado. Ya en Ruiz Manero 1990, pp. 38-45, hay referencias a esta posición luego refrendada por el autor en Ruiz Manero 2005.

${ }^{42}$ La posición seminal de Alchourrón y Bulygin se encuentra en 1987, p. 216. Una respuesta más reciente a la postura compartida de Atria y Ruiz Manero se halla en Bulygin 2003, pp. 7-25. Véanse Atria 2001, pp. 76-86 y 2005, pp. 20-21.

${ }^{43}$ Agradezco las correcciones que los árbitros hicieron a este trabajo pues, sin duda, redundan en una mayor calidad del mismo. Espero haber podido satisfacer sus expectativas. Además de ellos, David Martínez Zorrilla, Paolo Comanducci, Lucas Grosman, Marcelo Alegre, Claudio Viale y Rodrigo Sánchez Brígido me han formulado útiles sugerencias. 
Atienza, M. y J. Ruiz Manero, 2001, “La dimensión institucional del Derecho y la justificación jurídica", Doxa, Cuadernos de Filosofía del Derecho, no. 24, pp. 115-130.

Atria, F., 2001, On Law and Legal Reasoning, Hart, Oxford.

Atria, F., E. Bulygin et al., 2005, Lagunas en el derecho, Marcial Pons, Madrid.

Bayón, J.C., 1991, Normatividad del Derecho. Deber jurídico y razones para la acción, Centro de Estudios Constitucionales, Madrid.

Bobbio, N., 1965, El problema del positivismo jurídico, trad. Ernesto Garzón Valdés, Eudeba, Buenos Aires.

Brandom, R., 2002, La articulación de las razones. Una introducción al inferencialismo, trad. Eduardo de Bustos y Eulalia Pérez Sedeño, Siglo XXI, Madrid.

Bulygin, E., 2003, "Los jueces. ¿Crean derecho?”, Isonomía. Revista de Teoría y Filosofía del Derecho, no. 18, pp. 7-25.

Conee, E., 1982, "Against Moral Dilemmas", The Philosophical Review, vol. 90, no. 1, pp. 87-97.

Crisp, R., 2000, "Particularizing Particularism", en Hooker y Little 2000, pp. $23-47$.

De Haan, J., 2001, “The Definition of Moral Dilemmas: A Logical Problem”, Ethical Theory and Moral Practice, vol. 4, no. 3, pp. 267-284.

Delgado Pinto, J., 1996, "Normatividad del Derecho", en Ernesto Garzón Valdés y Francisco Laporta (comps.), El derecho y la justicia, Trotta, Barcelona, pp. 425-440.

Dworkin, R., 1996, "The Moral Reading of the Constitution", The New York Review of Books, vol. 43, no. 5, 21 de marzo, pp. 46-50. (Reimpreso en la introducción a Freedom's Law. The Moral Reading of the American Constitution, Harvard University Press, Cambridge, Mass., 1996, pp. 1-38.)

Hooker, B. y M. Little (comps.), 2000, Moral Particularism, Clarendon Press, Oxford.

Irwin, T.H., 2000, "Ethics as an Inexact Science: Aristotle's Ambitions for Moral Theory", en Hooker y Little 2000, pp. 100-129.

Kant, I., 2004 (1784), "Idea de una historia universal desde el punto de vista cosmopolita", Filosofía de la historia. Qué es la Ilustración, trad. Emilio Estiú y Lorenzo Novacassa, Caronte Filosofía, La Plata.

Kennedy, D., 1986, "Freedom and Constraint in Adjudication: A Critical Phenomenology", Journal of Legal Education, vol. 36, pp. 518-562.

Kolenda, K., 1975, "Moral Conflicts and Universalizability", Philosophy, vol. 50, pp. 460-465.

MacCormick, N., 1998, "Norms, Institutions and Institutional Facts", Law and Philosophy, vol. 17, no. 3, pp. 301-345. Oxford. 
MacCormick, N. y O. Weinberger, 1986, An Institutional Theory of Law. New Approaches to Legal Positivism, D. Reidel, Dordrecht.

McConnell, T., 2002, "Moral Dilemmas", Stanford Encyclopedia of Philosophy, en: http://plato.stanford.edu/entries/moral-dilemmas

McDowell, J., 1998, "Virtue and Reason", Mind, Value and Reality, Harvard University Press, Harvard, pp. 50-73.

Melville, H., 1998, Billy Budd, 3a. ed., y trad. Julia Lavid, Cátedra, Madrid.

Moreso, J.J., 2001, "Principio de legalidad y causas de justificación", Doxa, Cuadernos de Filosofía del Derecho, no. 24, pp. 525-545.

Navarro, P., 2005, "Casos difíciles, lagunas en el derecho y discreción judicial", en Atria, Bulygin et al., 2005, pp. 87-101.

Raz, J., 2000, "The Truth in Particularism", en Hooker y Little 2000, pp. $48-78$.

, 1991, Razón práctica y normas, trad. Juan Ruiz Manero, Centro de Estudios Constitucionales, Madrid.

— 1990, "Introduction", en Joseph Raz (comp.), Authority, New York University Press, Nueva York.

- 1988, "Incommensurability", The Morality of Freedom, Clarendon Press, Oxford, pp. 321-366.

Rodríguez, J., 1999, "Lagunas axiológicas y relevancia normativa”, Doxa. Cuadernos de Filosofía del Derecho, no. 22, pp. 349-369.

Ruiz Manero, J., 2005, "Algunas concepciones del derecho y sus lagunas", en Atria, Bulygin et al. 2005, pp. 103-126.

, 1990, Jurisdicción y normas, Centro de Estudios Constitucionales, Madrid.

Weinrib, E., 1995, The Idea of Private Law, Harvard University Press, Cambridge, Mass.

Williams, B., 1993, "Conflicto de valores", La fortuna moral, trad. Susana Marín, Universidad Nacional Autónoma de México, México, pp. 97-110.

Winch, P., 1972, "The Universalizability of Moral Judgments", Ethics and Action, Routledge and Kegan Paul, Londres, pp. 151-170.

Wright, G.H. von, 1968, An Essay in Deontic Logic and the General Theory of Action, Acta Philosophica Fennica, North-Holland, Amsterdam.

Recibido el 3 de junio de 2006; revisado el 13 julio de 2007; aceptado el 29 de agosto de 2007. 